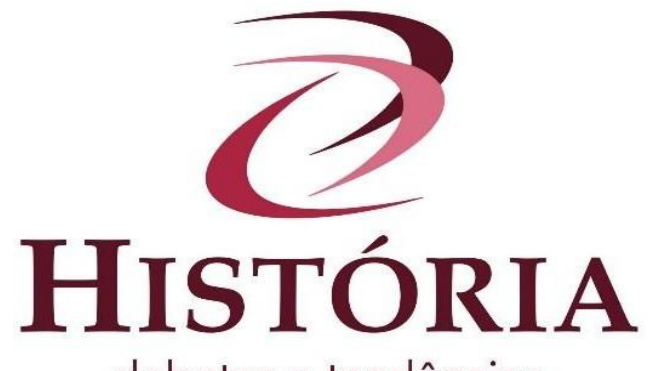

\title{
Poloneses no Espírito Santo: duas trajetórias de um povo entre os vales da Serra e os sertões do Norte
}

\section{Poles in Espírito Santo: two trajectories of a people between the valleys of the Sierra and the hinterlands of the North}

\section{Polacy w Espírito Santo: dwie historie imigrantów w dolinach Serra i w interiorze Pólnocy}

\author{
Maria Cristina Dadalto ${ }^{\mathrm{i}}$ \\ Renata Siuda-Ambroziak ${ }^{\text {ii }}$
}

Resumo: Este artigo visa apresentar o background histórico de trajetórias distintas de assentamento de dois diferentes fluxos migratórios de poloneses no estado do Espírito Santo: o primeiro, instalado no século XIX na Colônia de Santa Leopoldina, e o segundo, antes da Segunda Guerra, por meio de um contrato com a Sociedade de Colonização de Varsóvia, na região Norte do estado. Focamos o nosso estudo comparativo nas diferentes circunstâncias, razões e consequências da fundação dos dois assentamentos para demonstrar a importância das atitudes da sociedade receptora e políticas públicas para o sucesso da integração dos imigrantes poloneses na terra capixaba.

Palavras-chave: poloneses, migração, Brasil, o estado do Espírito Santo.

\begin{abstract}
This article aims to present the historical background of distinct paths of settlement of two different migratory flows of Poles in the state of Espírito Santo: the first, installed in the 19th century in the Colony of Santa Leopoldina, and the second, before World War II, through a contract with the Warsaw Colonization Society in the northern region of the state. We focus our comparative study on different circumstances, reasons and consequences of the foundation of the two settlements to demonstrate the importance of the attitudes of the receiving society and public policies for the successful integration of Polish immigrants in the land of Capixabas.
\end{abstract}

Keywords: Poles, migration, Brazil, the state of Espírito Santo.

Streszczenie: Celem artykułu jest przedstawienie historycznego kontekstu osiedlenia się w stanie Espírito Santo dwóch różnych fal imigracyjnych Polaków: pierwszej, skierowanej w XIX w. do Colônia de Santa Leopoldina, i drugiej, przybyłej przed II wojną światową, na podstawie kontraktu podpisanego z Towarzystwem Kolonizacyjnym z Warszawy, do północnej części stanu. W artykule przedstawione są w sposób porównawczy okoliczności, przyczyny oraz konsekwencje obydwu fal imigracyjnych w celu wykazania wagi stosunku społeczeństwa przyjmującego i polityki społecznej dla sukcesu integracji imigrantów polskich w Espirito Santo.

Słowa kluczowe: Polacy, migracja, Brazylia, stan Espírito Santo. 


\section{Introdução}

A chegada dos primeiros imigrantes poloneses no estado do Espírito Santo deu-se a partir dos anos de 1870. Nessa época eles foram assentados na recém-criada Colônia de Santa Leopoldina, de onde se espalharam para outros locais. Posteriormente, nos anos de 1929-1931, realizou-se novo fluxo migratório polonês, desta vez por meio de uma ação organizada pelo Governo Estadual e a Sociedade de Colonização (Towarzystwo Kolonizacyjne) da Polônia, com a criação do núcleo colonial de Águia Branca, no Norte do estado. Ao estabelecermos um paralelo entre esses dois fluxos, podemos observar diferentes formas de se organizar, perceber e receber esses grupos de poloneses pelas instituições e grupos étnicos assentes no Espírito Santo. O que motivou essas diferenças de atitudes e comportamentos? Quais as circunstâncias dos dois processos do assentamento dos poloneses nos dois lugares diferentes do estado? Quais as possíveis consequências delas para o sucesso de integração e visibilidade dos imigrantes poloneses dos dois grupos, para sua fixação permanente e relações sociopolíticas e interétnicas estabelecidas no território capixaba?

O que para nós se apresenta como uma hipótese plausível mais imediata é que os poloneses pioneiros têm, em comparação com o segundo fluxo, sua história pouco disseminada e conhecida entre a população regional não somente pelas condições difíceis da sua fixação no estado (chegados da pátria inexistente, ocupada pelas potências vizinhas, sem apoio institucional, com fatores adversos para sua plena integração: psicológicos complexo de inferioridade e animosidades frente aos grupos imigrantes provenientes dos países ocupantes na Europa; culturais - falta de educação, desentendimentos com grupos protestantes, especialmente luteranos; econômicos - pobreza extrema; sociais - construção de ambientes fechados para reconstruir a pátria perdida), mas, antes de tudo, por falta de estímulo e ajuda no lugar de assentamento por parte da sociedade local e do governo brasileiro. Já os imigrantes poloneses que vieram por meio da ação governamental nos anos de 1929/31 conseguiram potencializar melhor socioeconomicamente e politicamente o processo imigratório e o seu reconhecimento identitário, o que foi facilitado por melhores circunstâncias políticas da sua saída da Europa (a Polônia reconquistou a sua independência em 1918 e em seguida estabeleceu relações diplomáticas com o Brasil) e o desaparecimento de pelo menos alguns dos fatores adversos mencionados no caso do primeiro grupo, mas, 
antes de tudo - pela diferença na recepção deles no lugar de assentamento, notável nas atitudes e empenho político e administrativo do governo estadual.

Portanto, apesar de acreditarmos profundamente nas relações dialéticas entre os imigrantes e a sociedade receptora, onde atitudes, normas de comportamentos e valores dos dois lados influenciam-se reciprocamente (de uma maneira positiva ou negativa), enfraquecendo ou reforçando as fronteiras étnicas, sociais, culturais, econômicas, etc., nos concentramos neste artigo no impacto para o grupo polonês da sociedade receptora em termos das atitudes e comportamentos por parte das suas autoridades políticas e grupos étnicos e sociais existentes, chegados antes ou simultaneamente, no mesmo lugar de assentamento no estado. Como nota Bitterly (1989), as estratégias dos imigrantes na sociedade receptora variam desde a plena integração, através da aculturação, até tendências para separação e auto-marginalização. No entanto, nós procuramos, em vez de promover prejulgamentos sobre estratégias específicas dos dois grupos migratórios poloneses, lançar nosso olhar na sociedade local e nas suas instituições. Nesse respeito Sayegh e Lasry (1993) sublinham a importância das políticas, estratégias e atitudes da sociedade receptora frente aos imigrantes, reparando na prioridade das mesmas para o sucesso de integração e mencionando as varias tendências: desde os investimentos visando a rápida inclusão dos imigrantes, através das políticas sociais e culturais de apoio rumo à assimilação, até as situações, que promovem segregação e exclusão social, econômica e cultural do grupo imigratório, demostrando a rejeição do grupo pela sociedade receptora.

Para atingir os nossos objetivos, procurando as respostas às apresentadas perguntas norteadoras da pesquisa, propomos dividir o artigo em três partes: a primeira - tratando do primeiro fluxo, ainda no contexto do período imperial, com a fundação da Colônia de Santa Leopoldina e o Núcleo Timbuhy; a segunda - sobre o segundo fluxo, com a fundação da Colônia Águia Branca, que depois deu origem à criação do município homônimo; por fim, pretendemos resgatar os elementos de nossa hipótese e debater as possíveis ressonâncias resultantes das ações institucionais e da sociedade promovidas junto aos grupos imigratórios em geral e imigrantes poloneses em particular, entendendo melhor as estratégias aplicadas e comportamentos resultantes delas no lugar.

Para o desenvolvimento teórico-metodológico do artigo recorremos aos documentos disponíveis no Arquivo Público do Estado do Espírito Santo (APEES), iii muitos deles digitalizados, como relatórios de Presidentes de Província, no período imperial e Mensagens de Presidentes do Espírito Santo, no período republicano. Além disso, os livros digitais da 
Coleção Canaã e pesquisas acadêmicas, bem como imagens fotográficas e cartográficas compõem o levantamento para dar base ao nosso debate.

Importante avaliar, antes de passarmos para apresentar a primeira leva dos poloneses no território capixaba, que já a partir dos anos 20 do séc. XIX, o estado do Espírito Santo viu a entrada de diversos grupos étnicos europeus, sírios, libaneses e asiáticos. A partir do ano de 1847, com o desenvolvimento de um projeto político consolidado tendo em vista o fim da escravidão no país e visando atrair europeus para o Brasil (SEYFERTH, 2002), foram levadas em curso pelo governo imperial várias ações. Destacaram-se aquelas voltadas à propaganda da imagem civilizatória do país por meio da participação do Brasil nas Feiras Internacionais de Viena (SCHUSTER, 2015). Com isso, começaram a ser estabelecidos mais imigrantes, desta vez alemães, pomeranos, poloneses, suíços, holandeses, tiroleses, italianos. Sírios e libaneses se deslocaram independentemente da política de atração e de apoio governamental, bem como os poucos chineses que chegaram. No Arquivo Público do Estado do Espírito Santo há uma lista nominal de 54.155 estrangeiros que entraram no estado nos séculos XIX e XX (FRANCESCHETTO, 2014). Parte dos imigrantes europeus obteve terras, especialmente com a criação, em 1876, da Inspetoria Geral de Terras e Colonização, responsável pela definição de uma orientação unitária à introdução de imigrantes europeus no país (TRENTO, 1989). O modelo de colonização adotado pelo governo imperial embutia subliminarmente todo o conteúdo do projeto eurocêntrico colonizador, visando assim dar suporte à construção do mito do Brasil como um país civilizado, com progresso e desenvolvimento econômico. A proposta era de se contrapor a ideia de um país da barbárie, constituído de indígenas e negros (QUIJANO, 2000). Um modelo urdido de forma burocrática, elitista e inteligentemente arquitetada, cujos arquétipos representacionais, estruturas e dinâmicas devastadoras propostas no conceito de “embranquecimento da raça” se perpetuaram no país.

\section{Os primeiros poloneses}

Quando começamos a lançar nossos olhares para entender a imigração polonesa no Espírito Santo, uma constatação se apresentou confusa: porque, ela sendo importante, a quinta no número total de imigrantes no estado, ficou tão pouco debatida em nível sociocultural? É reconhecido entre os estudiosos da imigração estrangeira, que a maioria absoluta de imigrantes internacionais assentados no Espírito Santo, nos séculos XIX e XX, é de italianos. Mas tal é o nível de hibridização cultural realizado no estado capixaba em 
todos os seus níveis, presente em suas dinâmicas socioeconômicas, políticas, territoriais, culturais e psíquicas, que essa pergunta se mantém candente.

De modo que estabelecemos como meta a proposta de entender a vinda dos imigrantes poloneses pioneiros para o Espírito Santo a partir da fixação desse grupo na Colônia de Santa Leopoldina (Tabela 1 a seguir), a maior do estado e uma das maiores do Império, fundada em 1857. Essa Colônia continha uma diversidade de grupos estrangeiros assentados e teve seu início relativamente conturbado, especialmente pela seleção inapropriada das terras destinadas ao primeiro grupo de colonos estabelecidos, os suíços (SOPRANI, 2015).

De acordo com o levantamento realizado por Franceschetto (2014) no APEES, chegaram no Espírito Santo 698 imigrantes poloneses ainda no Novecentos, a maioria vindos da região da Prússia Oriental. Desse quantitativo, 95\%, ou 658 poloneses, foram fixados na Colônia de Santa Leopoldina; 3,32\% (23), em Porto Benevente; e 1,44\% (10), em Piúma. Os dados de Franceschetto esclarecem ainda que o total de imigrantes que entraram no século XIX, vieram em duas levas: nos anos de 1870, com a chegada de 575 pessoas; e em 1880, com a entrada de 123. Mas, parte daqueles que chegaram entre os anos de 1872-1873 se retiraram para o Sul do país. ${ }^{\text {iv }}$

Tabela 1: Poloneses que chegaram ao ES no Século XIX de acordo com as regiões de origem.

\begin{tabular}{|l|l|l}
\hline REGIÕES & IMIGRANTES & $\%$ \\
\hline Prússia Oriental & 553 & 88,1 \\
\hline Sob o domínio da Rússia & 54 & 8,6 \\
\hline Sob o domínio da Prússia & 19 & 3,0 \\
\hline Outros & 2 & 0,3 \\
\hline Sem Referência & 70 & \\
\hline
\end{tabular}

Fonte: Franceschetto, 2014.

Os imigrantes poloneses eram predominantemente agricultores pobres e católicos. A primeira leva aportou nos navios Zorida e Hertig Oscar Friederick, no porto de Vitória em dezembro de 1872, vindos de Hamburgo, Alemanha.

Posteriormente, entre os meses de maio e julho de 1873, atracaram mais 118 poloneses conduzidos pelos navios Adolph e Gutenberg, desta vez procedentes da Prússia 
Ocidental. Nos mesmos navios também embarcavam para o Espírito Santo camponeses pomeranos, na maioria luteranos.

Ao desembarcar no porto de Vitória, capital da Província do Espírito Santo, os imigrantes foram conduzidos à Colônia de Santa Leopoldina que efetivamente não se encontrava preparada para recebê-los. Já com muitos problemas com os colonos alemães, suíços, e outros que habitavam o lugar, os poloneses se depararam com acomodações precárias e insuficientes para a quantidade de colonos deslocados para o local. Além disso, era verão, período de forte calor nos trópicos, sem assistência médica, e tendo de aguardar para que se fizesse a demarcação dos lotes, e sem informações sobre os itens de sobrevivência numa terra absolutamente estranha à sua cultura, história e territorialidade.

Toda essa escassez de infraestrutura e omissão dos governantes com relação aos poloneses suscitou junto à parte do grupo uma grande revolta, provocando inclusive um movimento com armas contra autoridades da colônia. De acordo com Grosselli (2008), como resultado, em julho de 1873, muitos imigrantes haviam se movido de Santa Leopoldina em direção às colônias do Sul do país. Franceschetto (2014), assegura que algumas das famílias remanescentes foram as primeiras a ocupar o núcleo Timbuhy, situado nas cercanias do município de Santa Teresa.

Em 1874 o Governo criou dois estabelecimentos ligados à Colônia de Santa Leopoldina: o núcleo Santa Cruz e o núcleo Timbuhy. Esse último diretamente relacionado ao destino da trajetória dos poloneses que partem da Colônia e se instalam fundando o que se tornaria conhecido atualmente como Patrimônio dos Polacos. O Núcleo Timbuhy foi criado a partir da necessidade de ampliar o acesso às terras da Colônia de Santa Leopoldina, que vivia situação de desenvolvimento e saturação na ocupação dos espaços, e parte dos colonos tinham condições de dispensar a tutela do Estado, segundo informava o diretor interino Pedro de Sant'Anna Lopes ao presidente da Província, Domingos Gomes Peixoto, em ofício datado de 11 de julho de 1875, no qual esclarecia e justificava a fundação do núcleo (BUSATTO, 2002). Ainda segundo as explicações do diretor Lopes, os primeiros colonos do Timbuhy eram italianos e poloneses.

Segundo Grosselli (2008), os colonos poloneses já chegaram se sentindo sobressaltados. É o que indicava a direção da Colônia, em documento reproduzido por Grosselli (2008, p. 211), no qual o diretor se referia a algum tipo de acontecimento que acendera os ânimos daqueles colonos e era alusivo à entrega de documentos falsos relacionados às promessas da agência de emigração, Loniz Knoor e C., sobre o que os poloneses receberiam ao se estabelecer no Espírito Santo. Falavam de 9 meses, durante os 
quais a direção colocaria ao dispor dos imigrantes víveres, uma casa que encontrariam à sua disposição na chegada e de campos já cultivados. Das três, apenas a segunda promessa estava em consonância com a lei das colônias de 1867 .

Importante ressaltar que invenções de agentes de emigração visando lucrar altas somas deslocando os imigrantes para o Brasil fez parte do jogo desumano: a miséria vivida por milhares na Europa e o sonho de um futuro mais próspero contra a desonestidade de agentes nacionais e internacionais. Contudo, foi outro problema que potencializou a raiva dos poloneses: parte foi hospedada em um velho e decrépito barracão; e parte, em um barracão ainda em construção, que quando chovia entrava água pela parede que não havia sido concluída. Também não tinha médico. Os poloneses escreviam petições às autoridades reclamando do reduzido valor do salário percebido pelo trabalho realizado na estrada, e o sacrifício que haviam feito ao vender todo o pouco que tinham na terra natal para vir para o Brasil. Protestavam também por não ter uma alimentação de qualidade, que para eles significava conter farinha de trigo e toucinho, assim como pelo custo muito alto na colônia e da impossibilidade de comprar víveres com o que ganhavam.

De acordo com Grosselli (2008), a Direção admitiu a inépcia para acolher os poloneses. Faltavam casas, os lotes não haviam sido medidos, não havia serviço médico. Mesmo assim tentava justificar suas ações, recorrendo a comparações injustificáveis com outros grupos ou situações. A situação foi-se agravando, com a morte de $3 \%$ dos poloneses em menos de oito meses do tempo que chegaram à colônia em janeiro. Segundo Grosselli, outro problema embaraçou ainda mais a relação entre os colonos poloneses e as autoridades da Colônia provocado por informações caluniosas disseminadas por um senhor conhecido por Tesch, de acordo com o diretor da colônia:

\begin{abstract}
A crassa ignorância e a ilimitada confiança desta gente levam-na a um estado de contínua perplexidade. Foram induzidos pelos maus conselhos de I. J. Tesch, que denegriu a colônia, afirmando até mesmo que morreriam de fome se não decidissem comer serpentes, e ajudou-os a reclamar junto ao Ministro, no Rio de Janeiro, lamentando-se de seu imaginário mau estado. Como disse, estão sempre perplexos e não aceitam mais conselhos de ninguém. Esforcei-me a dissuadi-los das caluniosas informações do Sr. Tesch, que há muitos anos emprega estes meios (a intriga) para obter a nomeação de agente consular (GROSSELLI, 2008, p.215).
\end{abstract}

Chama atenção como eram percebidos os poloneses nos documentos oficiais por presidentes, diretores de colônia e sobre como esses representavam a visão dos outros imigrantes sobre os poloneses. Especialmente alguns documentos nos advertem às variáveis políticas culturais passíveis de serem avaliadas num contexto externo e interno ao próprio Brasil e Espírito Santo. São fatos interligados e que apresentaremos a seguir: 
Já nos primeiros dias de permanência no Brasil, o diretor Da Cunha Bastos observava: "Devo declarar que antigos colonos aqui estabelecidos e também os pomeranos que vieram com os navios Zorida e H. Oscar Frederick não se ligam aos outros, por eles denominados "polacos" e pedem que sejam separados, afirmando que estes polacos são muito revolucionários e ladrões."

A direção confirmava as acusações dos alemães: "Sendo os colonos recém-chegados extremamente indisciplinados, tanto que violaram a propriedade alheia, forçando os negociantes a dar-lhes o que desejavam, e sendo considerável o número dos que se entregam à contínua embriaguez, eu, desprovido de todos os meios para reconduzi-los à ordem, venho respeitosamente suplicar a Vossa Excelência que se digne a tomar as medidas que julgar convenientes.” (GROSSELLI, 2008, p.215-216).

É de Daemon que apresentamos a transcrição do trecho abaixo e que também ficou conhecido como a "Revolta dos Polacos" em 1873:

Tratando da tranquilidade pública devo referir-vos, que, na Colônia de Santa Leopoldina ia sendo sensivelmente alterada a ordem e sossego público por uma turma de colonos polacos, que, em número de cem, talvez, sendo uns setenta armados, concentrou-se no Porto do Cachoeiro em atitude hostil à diretoria do estabelecimento e à população pacífica e laboriosa da localidade. Sendo-me oficialmente comunicada esta ocorrência, fiz seguir para ali uma força de linha, sob o comando do tenente Pedro José Ribeiro, para garantir a ordem...v (DAEMON, 2010, p. 464.).

Busatto (2002), explica que em relatório o Diretor da Colônia de Santa Leopoldina, Dr. Pedro de Albuquerque Rodrigues, remete ao Presidente da Província do Espírito Santo que após o conflito com os colonos negociou um mapa estatístico, no qual informa o nome de todos os 48 chefes de família polacas que receberam prazos: 31 na Colônia de Santa Leopoldina e 17 no Timbuhy; 27 ficaram em dúvida sobre a oferta; e que 59 recusaram e se retiraram para Vitória em duas turmas, 30 em 25 de julho e 29 em 29 de julho do mesmo ano; um ficou hospitalizado em Vitória. O total somava 135 famílias e o número médio de membros por família era de 5 pessoas. Por fim, o diretor conclui seu relatório:

\footnotetext{
A ociosidade, o descaramento, a ratonice, o gênio desordeiro são os caracteres distintivos do Polaco. Por conveniência e moralidade do serviço fui forçado a não deixar sequer um Polaco nas turmas em que trabalham os Alemães (Pomeranos) pois o seu contato era por demais sensível ao serviço. Essa gente foi como uma praga lançada sobre esta Colônia: a passagem de um grupo deles é sempre perfeitamente traçada pela destruição e roubo ou furto de algum objeto. Tudo lhes serve; alguém pode ficar tranquilo diante desses, talvez, antigos fregueses das casas de correção de Possen? Alguém julga-se tranquilo diante desses verdadeiros bandidos? (BUSATTO, 2002, p.82).
}

Poderíamos nos perguntar quais as motivações endógenas e exógenas dos demais grupos imigrantes assentados na Colônia de Santa Leopoldina para agir com tanta rispidez contra os poloneses. Uma possível pista exógena e de origem nacionalista pode ser ofertada 
por Oliveira (2015), em discussão que faz sobre uma descoberta do sociólogo Octávio Ianni e o racismo contra os poloneses em Curitiba. No seu relato, Oliveira (2015, p.811 apud Ianni, 1961: 384), assegura que a provável gênese do preconceito nesse processo de integração social esteja vinculada a "marcas raciais ou avaliações positivas ou negativas [...] manipuladas sociologicamente", e incorporadas, pela comunidade, a partir de elementos da ideologia racial dos alemães que a trouxeram da Europa.

É possível deslocar o sentimento da ideologia racial dos alemães e do espírito de superioridade deste contingente imigratório frente aos povos vizinhos, subjugados politicamente na Europa e ainda representando uma outra crença. Mas achamos, referindo à nossa hipótese, que os estereótipos prejudiciais se estenderam junto aos demais grupos étnicos europeus contra os poloneses também em vista de uma grande escassez de recursos para dividir no lugar de assentamento e da inconsequência e ineficácia dos serviços prometidos e nunca prestados para eles por agentes públicos e privados, influindo na capilaridade das relações estabelecidas. A exibição das diferenças e conflitos acontece sempre quando os mecanismos existentes (políticos, econômicos, sociais) são insuficientes e começam a beneficiar alguns grupos percebidos como mais desejáveis do que outros. Huntington (1998) afirma que os povos se alinham em blocos antagônicos porque são diferentes e essas diferenças são fatores causadores de antagonismos. Mas, nós supomos que pode acontecer ao contrário: a linguagem política, decisões do poder, interesses na escala micro e macro, obrigam as pessoas para demarcar seus territórios étnicos, culturais e físicos. Acreditamos que não foi diferente nos finais do século XIX no Espírito Santo: os grupos migratórios chocavam-se em disputa pelos recursos, exacerbando as suas diferenças, distinções e conflitos.

Entre os imigrantes poloneses que se estabeleceram no núcleo Timbuhy, fundando o Patrimônio de Santo Antônio do Canaã ou Patrimônio dos Polacos, destacam-se 17 sobrenomes, conforme Tabela 2:

Tabela 2: Nome dos Imigrantes Poloneses estabelecidos no Núcleo Timbuhy.

\begin{tabular}{|c|c|c|}
\hline Nome & Qtdade. Membros Família & Navio de Atracação \\
\hline Franz Okonski & 7 & Zorida \\
\hline Joseph Ziemanoski & 5 & Zorida \\
\hline João Hasse & 5 & Zorida \\
\hline João Hasse (Filho do anterior) & - & Zorida \\
\hline Valentin Gdanitz & 6 & Zorida \\
\hline Joseph Eiclolz & 3 & H.O. Frederick \\
\hline
\end{tabular}




\begin{tabular}{|c|c|c|}
\hline Johan Selenski & 3 & H.O. Frederick \\
\hline Johan Latozewski & 6 & H.O. Frederick \\
\hline Johan Fiertalski & 4 & H.O. Frederick \\
\hline Joseph Grabowski & 5 & H.O. Frederick \\
\hline Franz Pszecka & 5 & H.O. Frederick \\
\hline Johan Dobrowoski & 5 & H.O. Frederick \\
\hline Franz Grabowski & 6 & H.O. Frederick \\
\hline Thomaz Grabowski (filho do & - & H.O. Frederick \\
\hline anterior) & & H.O. Frederick \\
\hline Augusto Quanta & 5 & Marie Heydon \\
\hline Joseph Shilitz & 5 & Marie Heydon \\
\hline Thomaz Shilitz & 3 & \\
\hline
\end{tabular}

Fonte: Busatto (2002, p.83-84).

De acordo com Rocha (2000), o processo imigratório de assentamento de estrangeiros no território capixaba se desenvolveu em três fases: 1847 a 1881, 1882 a 1887, e 1888 a 1896, tal como podemos verificar na Tabela 3 a seguir, ordenada pelos 5 países com maior quantitativo de imigrantes assentados (e registrados regularmente) no APEES. Necessário situar que as fronteiras do Espírito Santo com Minas Gerais, Rio de Janeiro e Bahia sempre foram muito fluídas, portanto havia muita mobilidade migratória inter-regional. Os dados levantados pelo APEES são aqueles referentes aos registros oficiais.

Tabela 3: Os principais países emissores de emigrantes para estado Espírito Santo (séc. XIX).

\begin{tabular}{|c|c|}
\hline Países & Sec. XIX \\
\hline Itália & 35.033 \\
\hline Alemanha & 4.013 \\
\hline Espanha & 2.942 \\
\hline Portugal & 2.080 \\
\hline Polônia (ocupada) & $699^{\mathrm{vi}}$ \\
\hline
\end{tabular}

Fonte: Franceschetto, 2014.

De 1830 a 1889, o Espírito Santo teve no comandado 55 presidentes provinciais deslocados de outras Províncias e por curtos períodos temporários, sendo que a vice-presidência cabia aos latifundiários locais, bem como os postos administrativos eram ocupados pela elite regional 
(BANCK, 1977). É relevante entender tal contexto no cenário das disputas internas e externas dos agentes sociopolíticos que moviam as peças das engrenagens das disputas locais e nacionais, e estavam presentes na tessitura internacional.

Em nível micro regional, as relações e ações realizadas por presidentes, vice-presidentes e diretores de colônias eram fontes de tensões conjunturais e estruturais, muitas vezes alusivas à alocação de dinheiro público, por exemplo. As tomadas de decisão de qualquer um desses agentes reverberava diretamente no desenho das rotas de estradas e dos lugares para a construção de pontes, o que também impactava em outras possibilidades de desenvolvimento socioeconômico e político do lugar e região do Espírito Santo daquele período. De modo que no século seguinte, a entrada de novos imigrantes poloneses aconteceu em outra tessitura.

\section{Poloneses em Águia Branca}

Muito diferentemente da forma desorganizada e desestruturada que os imigrantes poloneses do Novecentos foram assentados, ocorreu a entrada do novo fluxo migratório no Espírito Santo no século XX, mais especificamente entre o final da década de 1920 ao ano de 1931. Nesse período deram entrada 685 colonos (FRANCESCHETTO, 2014), a maioria absoluta dos imigrantes que chegaram nas levas (Tabela 4) do projeto celebrado pelo Governo Estadual com a Sociedade de Colonização de Varsóvia, em contrato assinado em 6.10.1928 ${ }^{\text {vii }}$. O projeto foi engendrado com a proposição de demarcar terras devolutas ao norte do Rio Doce, na Colônia de Águia Branca, pertencente à época ao município de Colatina, fixando nela os colonos poloneses.

Tabela 4: Imigrantes poloneses chegados ao estado do Espírito Santo.

\begin{tabular}{c|c} 
Ano & Quantitativo \\
\hline 1929 & 172 \\
\hline 1930 & 345 \\
\hline 1931 & 168 \\
\hline 1938 & 38 \\
\hline 1939 & 19
\end{tabular}

Fonte: Franceschetto (2014).

Pelo acordo lavrado, o Governo do Estado concedia gratuitamente 50 mil hectares, num prazo inicial de 8 anos, a ser renovado por mais dois anos. As terras deveriam ser 
divididas pela Sociedade de Colonização de Varsóvia entre os imigrantes poloneses em 2000 lotes de 20 a 30 hectares. O compromisso assumido era de assentar 1.800 famílias por ano, quantitativo não atingido por motivos diversos. As primeiras famílias que chegaram casais menores de 60 anos, com filhos maiores de 13 - eram compostas, em média, por seis pessoas (PACHECO; IGNATOWSKI, 1972, p. 3). Em conformidade com Franceschetto (2014), nessa Colônia foram fixados 777 camponeses - representando $86 \%$ do total da leva imigrante do Oitocentos. Mas permaneceram na capital Vitória 87 poloneses de profissões diversas, e 34 foram deslocados para outros municípios do estado. Há referências sobre as regiões de origem para 22\% dos imigrantes, sendo que majoritariamente vieram da Mazóvia - 47 indivíduos; da Podláquia - 28; Subcarpácia - 24; arredores de Łódź - 13 e Lublin, 9; e da região de Santa Cruz - 9. Vinte e oito imigrantes foram oriundos de distritos que pertencem atualmente à Ucrânia (FRANCESCHETTO, 2014).

O estabelecimento desses colonos compunha um plano de crescimento socioeconômico da elite política e econômica do estado dos Presidentes Florentino Ávidos (1924-1928) e Aristeu Borges de Aguiar (1928-1930). Bem como estratégia para controlar a exploração das terras do Espírito Santo em ação de mineiros, e de baianos, que procuravam novas áreas devolutas (EAGLER, 1962). Nesse sentido, estava em curso há alguns anos, movimento colonizador da população de fronteira integrado por uma frente de fazendeiros criadores de gado e por plantadores de café; além da intensa atividade de extração de madeira a ser comercializada no sul do país (LIMA, 2000).

O Presidente do Estado, Aristeu Borges de Aguiar, em mensagem lida na abertura da $1^{\text {a }}$ Sessão Ordinária da $13^{\text {a }}$ Legislatura ao congresso em 01.01.1928 viii chama atenção para as ações que vinham sendo desenvolvidas por seu antecessor Florentino Avidos. Na ocasião, ratifica a necessidade de reforma de leis, tendo em vista a importância de melhorar o serviço de ocupação de terras.

Posteriormente, em mensagem a $3^{\mathrm{a}}$ Sessão da $13^{\mathrm{a}}$ Legislatura a 22.09.1930, Aguiar deslinda o que considera imprescindível para regulamentar o Serviço de Imigração e Colonização para melhor atender às necessidades do estado, e desse modo solucionar problemas de ocupação de terras. Para o Presidente do Estado, a esse Serviço estava destinado um papel de potencial importância para a economia capixaba, e que o estado sentiria o seu resultado objetivo no futuro. Assegura nessa mensagem: 
Temos com que compensar fartamente o sacrifício do imigrante. A nossa terra é boa e ameno o clima. As nossas matas são virgens e um sem número de rios, córregos e riachos banham o nosso solo, de sorte que não temos regiões inóspitas nem infecundas. Ha carência de braços e assim, precisamos da cooperação estrangeira para compartilhar do nosso trabalho e da nossa fortuna (AGUIAR, 1930, p. 121).

Elucida ainda na mensagem que o Serviço de Imigração e Colonização não estava regulamentado, medida que considerava indispensável. Mas para atender às imposições, o governo havia construído alojamentos na capital, Vitória, e no município de Colatina, para receber as levas de imigrantes que chegavam pelo porto por meio do cumprimento das cláusulas do contrato efetuado com a Companhia Colonizadora de Varsóvia. Aguiar esclarece ainda que, de acordo com as normas do contrato celebrado, o Estado era o responsável pela alimentação e pelo transporte dos colonos que atracavam até o assentamento em Águia Branca.

A fixação dos colonos poloneses no norte do Espírito Santo se configurava, portanto, como um plano político e econômico visando: 1) controlar a frente agrícola em crescimento na fronteira Norte constituindo uma estrutura de expansão; 2) reforçar o ethos eurocêntrico racial de superioridade do trabalhador branco. Para Willems (1946) um dos fatores que reforçava este projeto político econômico era a construção da ponte sobre o rio Doce, em Colatina, iniciada no governo de Florentino Ávidos e não totalmente concluída no de Aristeu Borges de Aguiar, e que permitia um trânsito de ligação com a região norte, ainda não explorada economicamente.

Segundo Malacarne (2000), as primeiras famílias polonesas se instalaram em Águia Branca no ano de 1929. Elas aportavam em Vitória e de lá eram encaminhadas para Colatina. Na cidade então, tinha início a viagem pela floresta densa: de lá havia um caminhão que as transportava até o Aldeamento do Pancas (onde dormiam) para depois seguirem, a pé e com as crianças dentro de caixotes no lombo de animais, até a Colônia de Águia Branca. ${ }^{\mathrm{ix}}$ No núcleo já encontravam algum movimento, pois os primeiros nacionais já estavam ali fixados desde o ano de 1926. Todo o percurso compreendeu $219 \mathrm{~km}$.

Ao chegar ao núcleo colonial, os colonos recebiam um livreto, cujo título era Orzet Biały - uma Águia Branca, símbolo da Polônia, com as regras de convivência (MALACARNE, 2004). O estabelecimento do grupo ocorreu em condições ambientais difíceis e muito diferentes daquelas que eram acostumados na terra de origem, mas a estrutura organizativa de recepção se deu de forma muito diversa da que ocorreu com os imigrantes que chegaram no século XIX. De modo que eram alojados em dois grandes 
barracões (de 25 metros de comprimento por 8 de largura), divididos em três grandes salões, e dentro deles as famílias eram separadas por cortinas.

A situação de assentamento e ambientação ao clima, contudo, não foi satisfatória para todos os colonos. Nessa direção, imigrantes se deslocaram para o Paraná, São Paulo e para outras cidades do Espírito Santo. Alguns emigraram para outros países, e outros decidiram pela migração de retorno à Polônia (PACHECO; IGNATOWSKI, 1972).

Entretanto, o fluxo migratório polonês para o Espírito Santo no século XX não se diferenciou do primeiro apenas pelo cumprimento do Governo às regras do contrato celebrado, no qual se arquitetou toda uma estrutura física para atendê-los, apesar de ainda incompleta. Mas também havia tanto por parte da sociedade local, como das instituições a certeza do acerto da decisão tomada com relação a imigração dos poloneses, apesar de sobressair em vários escritos uma palavra ou outra que indicam sombras e desconfianças.

Tais sentimentos podem ser conferidos em extratos de matérias jornalísticas publicadas na revista Vida Capixaba, em artigos de jornais que circulavam no estado, e em conferências publicadas nos anais e monografias realizadas por geógrafos e outros estudiosos. A exemplo, matéria publicada na revista Vida Capichaba, na qual se lê:

[...] Estabelecida por um contrato com a Companhia Colonizadora de Varsóvia a vinda de agricultores polacos, perfeitamente selecionados (grifo nosso), pode ter, como resolvido, no Espírito Santo, o problema imigratório.

[...] Seja-nos, entretanto, permitido resumir, aludindo à satisfação, que tanto nos deve patrioticamente contentar, com que se mostram, com que todos se apresentam, esses imigrados, que aqui estão para nos acompanhar na luta pela vida e compartilhar fraternalmente das nossas alegrias e tristezas (VIDA CAPICHABA, p. 4. 1930).

Observe-se, porém, que com relação ao sentimento da certeza da assertividade da imigração polonesa no Espírito Santo, era também compartilhada pelos membros das instituições parceiras do processo. Assim, podemos avaliar a carta testemunho do Padre Inácio Posadzy, após visita ao núcleo colonial em 1930:

Em Águia Branca o camponês polonês está dando o testemunho das suas aptidões colonizadoras. Sem medo, ele se dirigiu à selva como conquistador vitorioso, e onde grassava o selvagem indígena, onde o frêmito das onças assustava o viajante - ele se estabeleceu em definitivo. [...] Nada será capaz de deter a sua caminhada. E por onde passa o seu pé, brotam pés de mandioca, murmuram as verdes plantações de cana-de-açúcar e de milho (POSADZY, 2017). 
Juntos, os pioneiros, construíram logo a igreja de Nossa Senhora de Monte Claro padroeira dos poloneses - (Foto 1), o cemitério (Foto 2), dentre outras obras patrimoniais étnicas identitárias.

Foto 2: Igreja em construção (à esquerda) e capela do cemitério polonês de Águia Branca (à direita).
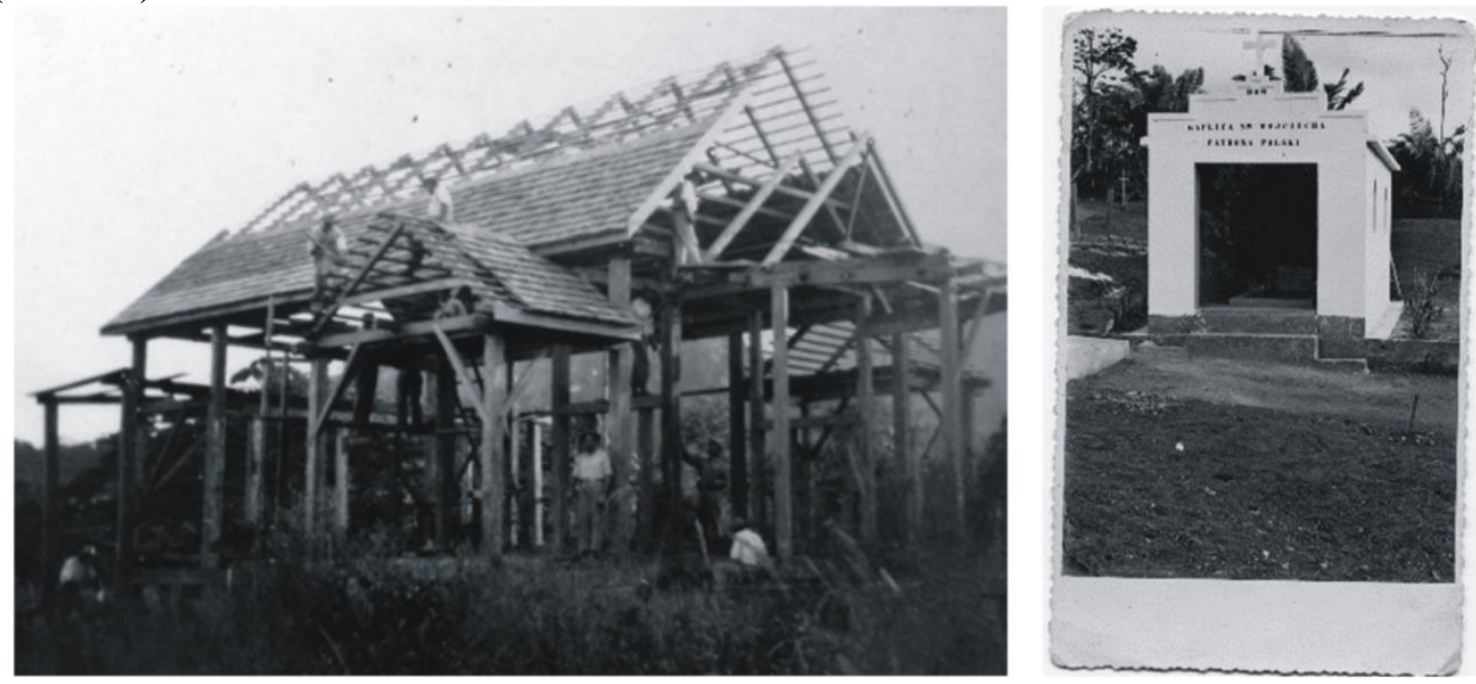

Acervo: Museu da Imigração.

Os poloneses teceram uma biografia, que, por óbvio, contou com influências e, às vezes, apoio e amizade dos brasileiros e de outros grupos de descendentes de imigrantes. Entrementes, a tessitura ordenada no século XX, não foi esvaziada de sofrimento, de dor da separação das suas histórias de vida individuais e coletivas, do enfrentamento de um território sociocultural e geográfico extremamente diverso daquele com o qual foram constituídos como sujeitos.

\section{Sentimentos dúbios}

Monografia produzida pelo engenheiro Antônio Araujo Aguirre, distribuída no VIII Congresso Brasileiro de Geografia, em Vitória e publicada em 1934, nos faculta a possibilidade de entender alguns aspectos desses momentos sociopolíticos e históricos que atravessaram a última metade do século XIX e o início do XX. Com o título Imigração e Colonização, em particular do estado do Espírito Santo, Aguirre faz uma apresentação ampla sobre o sentimento existente com relação aos imigrantes estrangeiros em geral no país, e, em especial, no estado, contextualizando um vislumbre do que pensavam operadores do planejamento público brasileiro. 
No primeiro momento, expõe sua percepção sobre o território que os imigrantes encontravam e o que entende que eles pensavam sobre as florestas:

\begin{abstract}
Do engano para o imigrante, ainda convencido que existem países maravilhosos, onde a conquista da riqueza não exige emprego de esforço (grifo nosso), se tem inconvenientes para a sociedade a sua orientação propagativa, concorre, no entanto, para ativar energias e desanuviar os sonhos, quando eles encaram a madeira que têm de talhar na floresta e o labor da cultura, demandando habilidade à conquista da fartura. (AGUIRRE, p. 10-15, 1934).
\end{abstract}

Explicita Aguirre seu pensamento sobre o imigrante, aquele que acredita que não precisa trabalhar para obter fartura. Mas logo em seguida, também assegura que eles não se deixaram intimidar e enfrentaram a densa mata, mudando inclusive o caráter, como faz entender após estabelecimento de contato que teve com um imigrante negociante: "O Snr. não pode imaginar a mudança para o Brasil como influi nos meus patrícios; este, por exemplo, que o Snr. viu sair, no Tirol, cumpriu sentença de crime de roubo e hoje cultiva bem seu lote, sendo um dos meus melhores fregueses." (AGUIRRE, p.16, 1934).

Contudo, ele apresenta a necessidade de se entender os diferentes estabelecidos por meio da política de colonização, entre os dois séculos. Inicialmente, avalia ser necessário entender que o futuro do país depende menos de seus recursos do que de sua orientação política. Até para fazer frente, de acordo com Aguirre (1934), a um discurso da mídia que clamava pela entrada de imigrantes, não importasse de qual país ou partido político. Acreditava ter claro que a colonização conduzida por meio da imigração estrangeira não deveria ser implementada como havia sido no Império.

Para Aguirre (1934) dever-se-ia pensar no patriotismo, e em consequência, na nacionalidade do estrangeiro. Isto porque considerava que colonizar as terras brasileiras era pensar nas novas regiões do ponto de vista social, das tradições, da cultura, das aspirações comuns e da assimilação. Aguirre avaliava ser o imigrante italiano o que melhor encarnava esse tipo ideal para o Espírito Santo. Ele faz comparações, explicando que os filhos dos alemães depois de assentados em Santa Leopoldina continuavam sem aprender a falar o português, já o italiano adaptou-se e se tornou brasileiro. Para Aguirre (1934, p. 61-62): “Os polacos, alemães, japoneses, vivem em seus núcleos segregados dos naturais e não representam papel importante na formação da nossa nacionalidade; sente-se em sua maioria um apego irresistível à velha mãe pátria.”

Em dezembro de 1930, ano de maior entrada de imigrantes poloneses no Espírito Santo, foi publicada pelo Governo Federal a primeira medida restringindo a imigração estrangeira no país; essa regulamentação foi se alterando até a fixação de cotas na 
Constituição de 1934. De modo que chegou-se, em 1937, a delimitar uma taxa anual de $2 \%$ sobre o quantitativo total de imigrantes já fixados no Brasil nos cinquenta anos anteriores à aprovação da lei no país no recorte temporal de 01/01/1884 a 31/12/1933.

Geraldo (2009) assegura que essa medida estava em consonância com debate promovido na Assembleia Nacional Constituinte, instalada em finais do ano de 1933, e provocada pela apresentação de emendas sobre imigração e colonização, fomentando questões desde miscigenação e assimilação até proteção ao trabalhador nacional.

Na época de Getúlio Vargas, políticas de nacionalização atingiram as populações de origem ou de ascendência estrangeira. Muitos foram considerados ameaça à formação da nacionalidade, em termos raciais ou culturais. Também a concentração de determinados grupos em núcleos coloniais (resultado das políticas anteriores de imigração) foi denominada como "quistos" étnicos ou raciais. Grande parte dessas etnias, inclusive a polonesa, eram europeias e vieram atraídas pelas políticas de incentivo imigratória do final do século XIX e início do XX, por meio do fortalecimento administrativo-burocrático governamentais.

Para Lanza e Lamounier (2015, apud SANCHEZ-ALONSO, 2007) havia uma crença que a imigração europeia, em especial aqueles reputados como culturalmente superiores, também possibilitaria a construção de uma nação mais desenvolvida tecnologicamente, mais rica. Tais representações, elaboradas nos diversos campos sociopolíticos, econômicos, culturais, históricos e territoriais no Brasil na tensão das relações estabelecidas pelas elites em disputas nas diversas regiões do país, ganhou espaço de convergências, divergências e imaginários férteis entre sociedade, imigrantes e instituições. Tal como foi expresso nos diversos discursos e estudos aqui elencados, que contribuíram para as diferenças notáveis entre os graus de aceitação sociocultural das sucessivas levas de imigrantes poloneses, sua recepção no estado e, consequentemente, também o sucesso ou a falha das políticas imigratórias realizadas.

\section{A guisa da conclusão}

Passados mais de um século da imigração polonesa para o Espírito Santo constatamos em pesquisas memorialísticas, artigos científicos e jornalísticos publicados, a diversidade como os dois principais fluxos foram absorvidos em nível regional. Confirmamos, que contextos sociopolíticos e históricos diversos estavam presentes nas duas 
fases, referendando ou desconstruindo a importância do papel que os imigrantes buscavam construir.

De um lado, percebemos uma potencialização identitária da etnia polonesas pelos descendentes dos colonos instalados em Águia Branca, de outro, uma quase invisibilidade do grupo que se estabeleceu em Santo Antônio do Canaã. Importante destacar também que as fontes documentais sobre a vinda dos poloneses no Novecentos são múltiplas, heterogêneas e com facilidade de acesso. Situação inversa à verificada para o grupo do Oitocentos: os documentos são raros e concentrados, sobretudo, no APEES.

Nenhuma dessas diferenças é substancial para discriminar ou desqualificar qualquer um desses fluxos, mas as duas, percebidas na perspectiva comparativa, se constituem como poderosos marcadores para nos fazer compreender a importância da ação da sociedade e das instituições no processo de assentamento e de recepção do migrante. Os impactos, ainda no presente, são sentidos pelas gerações de seus descendentes, com muitos deles buscando nas escavações históricas do passado compreender o processo de construção identitário étnico do qual fazem parte.

Introduzindo a distância entre representações e práticas nos dois contextos imigratórios poloneses no estado do Espírito Santo, tentamos reconhecer a não coincidência entre as várias manifestações de um grupo étnico polonês e a realidade enunciada no Brasil, no sentido das ações postas em prática pelos agentes colonizadores, o governo estadual e federal, assim como atitudes por parte de outros grupos étnicos nas áreas demarcadas para colonização. Levamos em consideração que os imigrantes poloneses, vieram, na primeira leva, de um país inexistente, sem recursos jurídicos, diplomáticos ou econômicos, e na segunda - saindo de um país recém restituído, que, apesar de destruído pela Primeira Guerra Mundial e saqueado pelos ocupantes, mostrava esforço institucional para ajudá-los. As tendências sociopolíticas e socioculturais diferentes no caso dos dois fluxos, afetaram os poloneses, assim como o comportamento dos agentes e as políticas que criavam e implementavam as estratégias imigratórias, de ordem financeira, organizativa, etc. Constatamos a existência do ambiente de tensões fortes interétnicas iminente aos deslocamentos em massa e a perpetuação de estereótipos e opiniões prejudiciais que vinham da Europa e se espalhavam no Novo Mundo, marcando os pioneiros poloneses. Acreditamos que os imigrantes carregam a heráldica de uma lealdade comum, que se institui em qualquer território que este grupo ocupa, especialmente quando a sua identidade é ameaçada. Isso ocorreu com a primeira leva, que se esforçava para manter os sinais de sua adesão étnica, emanando com a bagagem mental, com um estilo comportamental, com sua religiosidade, 
recriando a "velha pátria perdida", o que ajudava na sua coesão, mas dificultava a integração social, provocando vários atritos e despertando animosidades históricas (por exemplo com os alemães). Os poloneses do segundo grupo, convidados pelo governo do estado e participantes de uma ação oficial colonizadora, já estavam em condições de negociar seu status com outros, interagindo, pressionando pelo seu reconhecimento, apropriando-se mais das possibilidades de serem visualizados como um grupo importante, merecendo mais respeito por parte da sociedade receptora.

\section{Referências}

AGUIRRE, Antônio Aguiar. Imigração e Colonização, em particular do estado do Espírito Santo. VIII Congresso Brasileiro de Geografia. Niteroi, 1934. Monografia.

BANCK, Geert. Caçar com gato: escassez de recursos e relações sociais no Espírito Santo. 1977. Tese (Doutorado em Ciências Sociais) - Universidade de Amsterdam, Amsterdam, 1977

BITTERLY, Urs, Cultures in Conflict: Encounters Between European and Non-European Cultures. Stanford, CA: Stanford University Press, 1989.

BUSATTO, Luiz. Estudos sobre imigração italiana no Espírito Santo. Vitória, 2002. Reunião de artigos relacionados com imigração italiana, publicados em diversos periódicos. Reprodução autorizada pelo autor. Disponível em:

http://www.estacaocapixaba.com.br/2016/01/foto-guilherme-santos-neves-anos1950.html. Acesso em: 18.04. 2017.

CUNHA, Manuela Carneiro da (Org.). Legislação Indigenista no Século XIX: Uma Compilação (1808-1889). São Paulo: Edusp., 1992.

DAEMON, Basílio. Província do Espírito Santo: sua descoberta, história cronológica, sinopse e estatística. Coordenação, notas e transcrição de Maria Clara Medeiros Santos Neves. - 2.ed. - Vitória: Secretaria de Estado da Cultura; Arquivo Público do Estado do Espírito Santo, 2010. 684 p. : il. ; 20 cm X 24 cm. - (Coleção Canaã, v.12). Publicação em parceria com o Instituto Sincades. Disponível em:

https://ape.es.gov.br/Media/ape/PDF/Livros/Provincia_do_espirito_santo.pdf. Acesso em: 18.06.2020.

FRANCESCHETTO, Cilmar. Imigrantes Espírito Santo: base de dados da imigração estrangeira no Espírito Santo nos séculos XIX e XX. Organizado por Agostino Lazzaro. Vitória : Arquivo Público do Estado do Espírito Santo, 2014. 1.200 p. (Coleção Canaã ; v. 19). Disponível em:

https://ape.es.gov.br/Media/ape/PDF/Livros/Imigrantes_Livro_21_05_14.pdf Acesso em 14.03.2017.

Espírito Santo (Estado). Presidente Aristeu Borges de Águiar. Mensagem apresentada ao congresso legislativo na terceira sessão da décima terceira legislatura, em 22 de setembro de 1930 pelo Dr. Aristeu Borges de Águiar, 
presidente do Estado do Espírito Santo. Vitória, Imprensa Oficial, 1930. Disponível em: https://ape.es.gov.br/Media/ape/PDF/Mensagens/ARISTEU\%20BORGES\%20DE\%20ÁG UIAR\%20(3).pdf. Acesso em: 16.10.2017

GERALDO, Endrica. A "lei de cotas" de 1934: controle de estrangeiros no Brasil. Cad. AEL, v.15, n.27, 2009. Disponível em:

https://www.ifch.unicamp.br/ojs/index.php/ael/article/view/2575/1985. Acesso em 24.06.2019.

GROSSELLI, Renzo M. Colônias imperiais na terra do café : camponeses trentinos (vênetos e lombardos) nas florestas brasileiras, Espírito Santo, 1874-1900. [tradução Márcia Sarcinelli]. - Vitória : Arquivo Público do Estado do Espírito Santo, 2008. 534 p. : il. - (Coleção Canaã ; v.6). Disponível em:

https://ape.es.gov.br/Media/ape/PDF/Livros/Colonias_Imperiais_na_Terra_Cafe.pdf Acesso em: 24.06. 2012.

HUNTINGTON, Samuel, P. The Clash of Civilizations and the Remaking of World. New York: Simon\&Schuster, 1998.

Instituto Brasileiro de Geografia e Estatística (IBGE), (2010. Disponível em: https://cidades.ibge.gov.br. Acesso em: 19.11.2018.

LANZA, André Luiz; LAMOUNIER, Maria Lucia. A América Latina como destino dos imigrantes: Brasil e Argentina (1870-1930). Brazilian Journal of Latin American Studies, v. 14, n. 26, 2015) Disponível em: http://www.revistas.usp.br/prolam/article/view/102283. Acesso em 24.06.2019. DOI: https://doi.org/10.11606/issn.16766288.prolam.2015.102283

LIMA, Maria Helena Palmer. (2000). O processo de emancipação municipal no estado do Espírito Santo. Dissertação de Mestrado em Geografia. Programa de Pós-Graduação em Geografia da Universidade Federal do Rio de Janeiro.

MALACARNE, Altair. Águia Branca: uma rapsódia polono-brasileira na selva capixaba. São Gabriel da Palha: Gráfica Gomieri, 2004.

MALACARNE, Altair. São Gabriel da Palha. História da Origem. Nova Venécia: Gráfica Cricaré Ltda., 2000.

OLIVEIRA, Márcio. A inesperada descoberta de Otávio Ianni sobre preconceito contra descendentes de imigrantes poloneses em Curitiba. Revista Sociedade e Estado, Vol, 30, n.3, Set/Dez, 2015., p. 799:817.

PACHECO, Rogério; IGNATOWSKI, Wieslau Eustachio. Poloneses no Espírito Santo. Relatório Preliminar. Faculdade de Filosofia, Ciências e Letras. Colatina. Caderno de Cultura, n. 2. 1972. Mimeo.

POSADZY, Inácio. (2017). O início da colonização polonesa em Águia Branca - ES na descrição do pe. Inácio Posadzy. In: Revista Polonicus: Revista de Reflexão Brasil Colônia. Disponível em: http://www.polonicus.com.br/site/biblioteca_interna.php?cod=18 Acesso em 08.08.2017 (fragmentos do livro: POSADZY, Ignacy pe. Droga pielgrzymów. 
Wrażenia z objazdu osad polskich w Potudniowej Ameryce w latach 1929 oraz 19301931. 5.ed. Poznań: Towarzystwo Chrystusowe dla Polonii Zagranicznej, 1985.

QUIJANO, Aníbal. Colonialidad del poder, eurocentrismo y América Latina. In:

LANDER, Edgardo (Org.), La colonialidad del saber: eurocentrismo y

ciencias sociales. Perspectivas Latinoamericanas. Buenos Aires: CLACSO,

Consejo Latinoamericano de Ciencias Sociales, 2000, p. 201-46.

http://bibliotecavirtual.clacso.org.ar/ar/libros/lander/quijano.rtf

ROCHA, Gilda. Imigração estrangeira no Espírito Santo 1847-

1896. Vitória: [s.n.], 2000.

SAYEGH, L., LASRY, Jean-Claude. Immigrants Adaptation in Canada: Assimilation, acculturation and orthogonal cultural identification. In: Canadian Psychology, 34(1), p. 98-109, 1993.

SEYFERTH, Giralda. Colonização, imigração e a questão racial no

Brasil. Revista USP, São Paulo, n. 53, 2002, p. 117-149, mar.-maio.

SCHUSTER, Sven. The Pursuit of Human Perfection: Brazil

at the Vienna Universal Exhibition of 1873. Hist. Crit. No. 55, Bogotá, enero - marzo, 2015, pp 45-71. doi: dx.doi.org/10.7440/histcrit55.2015.03

TRENTO, Angelo. (1989). Do outro lado do Atlântico: um século de imigração italiana no Brasil. São Paulo: Nobel, 1989.

VIDA CAPICHABA, Ano VIII, nr. 228, Victória, 22 maio de 1930.

WILLEMS, Emílio. A aculturação dos alemães no Brasil. São Paulo: Cia Editora Nacional, 1946.

Submetido em: 30/07/2020

Aprovado em: 17/08/20200

Publicado: 23/09/2020

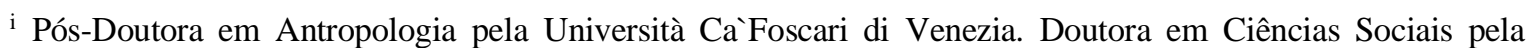
Universidade do Estado do Rio de Janeiro. Bolsista Pesquisadora da FAPES (Fundação de Amparo à Pesquisa no Espírito Santo). Professora do Departamento de Ciências Sociais da Universidade Federal do Espírito Santo. Professora dos Programas de Pós-Graduação em História e de Ciências Sociais da Universidade Federal do Espírito Santo.

ii Pós-doutora em Sociologia. Doutora em Filosofia Social e mestre em Estudos Sociais. Especialista em História Social da América Latina e bacharel em Filologia Inglesa. Professora e Coordenadora do Laboratório de Estudos Brasileiros da Universidade de Varsóvia.

iii Agradecemos o apoio do historiador Tiago de Matos Alves, do APEES, que nesse período de pandemia se disponibilizou a acessar documentos raros do Arquivo para a escrita desse artigo.

iv Sabemos que é um percentual alto, mas não conseguimos quantificar o total ainda. Fala-se, entre alguns pesquisadores da imigração de forma informal, na maioria.

${ }^{v}$ Fala dirigida à Assembleia legislativa Provincial pelo Exm. Sr. presidente da província do Espírito Santo Dr. João Tomé da Silva em ocasião da abertura de sua sessão ordinária..., 10 de setembro de 1873, Eleições, p. 4 (Daemon, 2010)
} 


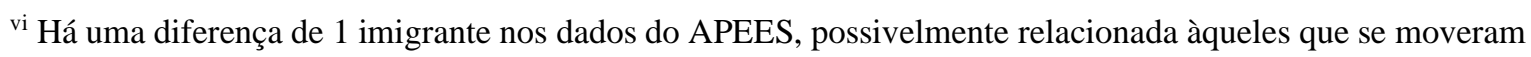
para outros estados do país.

vii Contrato lavrado no livro 25, fls. 30 a 35, V do Cartório dos Feitos da Fazenda de Vitória, Espírito Santo, por Boleslaw Giliczyński, membro do Conselho Administrativo da Sociedade de Colonização de Varsóvia (Pacheco; Ignatowski, 1972).

viii Disponível em https://ape.es.gov.br/relatorios-e-mensagens-2

ix A Colônia de Águia Branca foi transformada em distrito em 22.10.1949, criado com a denominação de Águia Branca, e vinculado ao município de Colatina, em 1988 elevado à categoria de município, de território de $454,448 \mathrm{~km}^{2}$, habitado pela população predominantemente rural de 9.519 pessoas (IBGE, 2018). A base de sustentação econômica do município é a agropecuária, destacando-se os cultivos de café e a pecuária de leite e corte. 